ЮРИСПРУДЕНЦИЯ

\title{
ПОРЯДОК ПРОВЕДЕНИЯ АТТЕСТАЦИИ ГОСУДАРСТВЕННЫХ ГРАЖДАНСКИХ СЛУЖАЩИХ РФ
}

\author{
И. А. Абрамов \\ (Московский гуманитарный университет)
}

\begin{abstract}
Аннотация: В статье рассматривается вопрос о порядке проведения аттестации государственных гражданских служащих РФ, раскрывается порядок формирования и работы аттестационных комиссии. Также в статье указываются решения, принимаемые по результатам аттестации.
\end{abstract}

Ключевые слова: государственный гражданский служащий, аттестация, отзыв, комиссия, решение.

\section{CERTIFICATION PROCEDURE FOR CIVIL SERVANTS IN THE RUSSIAN FEDERATION}

\author{
I. A. Abramov \\ (Moscow University for the Humanities)
}

\begin{abstract}
The article discusses the procedure for certification of civil servants in the Russian Federation and describes the formation and functions of certification committees. We also list the types of rulings which come after the certification.
\end{abstract}

Keywords: civil servant, certification, review, certification committee, ruling.

Аттестация имеет важнейшее значение в практической деятельности служащих, поскольку является правовым средством расширения демократических начал в кадровой политике и в управлении государственной службы, средством обеспечения формирования и реализации целенаправленной и предсказуемой кадровой политики в государственных органах, а также в формировании персонала управления в государственных органах.

Понятие аттестации раскрывается в основном в энциклопедической и специальной юридической литературе. В «Большом юридическом словаре» аттестация характеризуется, как свидетельство, определение квалификации работника, уровня знаний учащихся, отзыв или характеристику (Большой юридический словарь, 1998: 9). Энциклопедический юридический словарь понимает под аттестацией «определение квалификации работника с целью проверки соответствия занимаемой должности» (Юридический энциклопедический словарь, 1984: 26).

По мнению Н. Н. Булыги, аттестация - это процедура определения соответствия работника занимаемой должности или выполняемой ра- 
боте, а гражданского служащего - замещаемой должности гражданской службы (Булыга, 2009: 9). Н. М. Антонова указывает на то, что аттестация призвана обеспечить реализацию конституционного принципа равного доступа граждан РФ к государственной службе (Антонова, 2010: 49).

Закон № 79-ФЗ значительно сузил сферу аттестации как «правового регулятора государственной службы» (Колесников, 1999: 84), оставив за ней определение соответствия гражданского служащего замещаемой должности гражданской службы (ч. 1, ст. 48).

Аттестация необходима для регулярного определения уровня профессиональной подготовки служащего и степени ее соответствия квалификационным требованиям, предъявленным к государственным должностям государственной службы, а также для присвоения квалификационного чина. Совершенствование и упорядочение прохождения государственной службы невозможно без периодической аттестации и порядка аттестации служащих. Аттестация в узком смысле проводится с целью проверки и оценки профессиональных, деловых и личных качеств служащего, установление его служебно-должностного соответствия предъявляемым требованиям к службе. В ст. 48 Ф3 «О государственной гражданской службе РФ» от 27.07.2004 г. (Собрание законодательства Российской Федерации 2004: ст. 3215) определяется, что аттестация гражданского служащего проводится в целях определения замещаемой должности гражданской службы (Собрание законодательства Российской Федерации 2004. N31. Ст. 3215). Аттестация в более широком понимании решает следующие основные задачи: соблюдение на практике принципов государственной службы; обеспечение законности в системе функционирования государства; формирование профессионального кадрового персонала государственных органов; выявление потенциальных возможностей государственного служащего с целью повышения его по службе; применение к государственному служащему мер ответственности и стимулирования; повышение дисциплины и ответственности; поддержание стабильности государственной службы; стимулирование повышения квалификации и профессионализма служащих.

В ФЗ «О государственной гражданской службе РФ» устанавливается, что государственный гражданский служащий подлежит аттестации 1 раз в 3 года. Это общее правило проведения аттестации государственных гражданских служащих, и предполагается, что это оптимальный срок для оценки соответствия гражданского служащего замещаемой должности. Внеочередная аттестация гражданского служащего может проводиться после принятия в установленном порядке решения о сокращении должностей гражданской службы в государственном органе или об изменении условий оплаты труда гражданских служащих. Внеочередная аттестация 
гражданского служащего также может проводиться по соглашению сторон служебного контракта с результатом годового отчета о профессиональной служебной деятельности гражданского служащего. Необходимость проведения внеочередной аттестации в данном случае может возникнуть в связи с неудовлетворительными показателями деятельности государственного гражданского служащего, отраженными в годовом отчете. Однако следует учитывать, что в указанном случае внеочередная аттестация не может быть проведена, если не будет достигнуто соглашение между представителем нанимателя и гражданским служащим о проведении аттестации. Также по решению представителя нанимателя в лице руководителя государственного органа или представителя этого руководителя, осуществляющих полномочия представителя нанимателя от имени РФ или субъекта РФ, после принятия в установленном порядке решения: 1) при сокращении должностей гражданской службы в государственном органе аттестация проводится с целью определения гражданских служащих, которые обладают преимущественным правом оставления на работе в силу высокой результативности труда и высокой квалификации. По результатам внеочередной аттестации таким служащим могут быть предоставлены для замещения иные должности гражданской службы, а также в другом государственном органе. Но проведение аттестации в случае сокращения должностей является правом, а не обязанностью руководителя. 2) об изменении условий оплаты труда государственных гражданских служащих. Здесь внеочередная аттестация может быть проведена в целях выявления необходимости обеспечения обоснованности изменений оплаты труда гражданских служащих. Гражданский служащий, находящийся в отпуске по беременности и родам или в отпуске по уходу за ребенком до достижения им возраста 3 лет, походит аттестацию не ранее чем через 1 год после выхода из отпуска. Это объясняется тем, что за время отпуска по уходу за ребенком работник может потерять квалификацию и разумным сроком на ее восстановление является один год, а также при несоответствии с занимаемой должности все равно не позволит прекратить с служащим отношения по п. 3 ст. 81 Трудового кодекса РФ (несоответствия работника занимаемой должности или выполняемой работе вследствие недостаточной квалификации, подтвержденной результатами аттестации) (Шур-Труханович, 2006: 78).

В соответствии с ч. 7 данной статьи при проведении аттестации учитываются соблюдение гражданским служащим ограничений, отсутствие нарушений запретов, выполнение требований к служебному поведению и обязательств. При этом необходимо отметить, что соблюдение или не соблюдение гражданским служащим ограничений, отсутствие нарушений запретов, выполнение требований к служебному поведению и обязательств 
не является свидетельством того, что данный гражданский служащий не соответствует занимаемой должности по своим знаниям и навыкам, способности качественно и в срок выполнять свои должностные обязанности. Хотя несоблюдение гражданским служащим ограничений, нарушение запретов, невыполнение установленных требований к служебному поведению и обязательств ставят под сомнение право нахождения государственного гражданского служащего на государственной службе.

При проведении аттестации оцениваются следующие документы: подготовленный непосредственным руководителем государственного гражданского служащего мотивированный отзыв об исполнении гражданским служащим должностных обязанностей за аттестационный период; сведения о выполненных гражданским служащим поручениях и подготовленных им проектов документов, при необходимости- пояснительная записка гражданского служащего на отзыв непосредственного руководителя. В соответствии с пп. 12-13 Положения о проведении аттестации государственных гражданских служащих РФ, утвержденного Указом Президента РФ от 01.02.2005 г. № 110, указанный отзыв предоставляется в аттестационную комиссию не позднее чем за две недели до начала аттестации. Отзыв подписывается непосредственно руководителем государственного гражданского служащего, данный отзыв должен содержать следующие сведения о гражданском служащем: а) фамилия, имя, отчество; б) замещаемая должность гражданской службы на момент проведения аттестации и дата назначения на эту должность; в) перечень основных вопросов (документов), в решении которых гражданский служащий принимал участие; г) мотивированная оценка профессиональных, личностных качеств и результатов профессиональной служебной деятельности государственного гражданского служащего. При каждой последующей аттестации в аттестационную комиссию предоставляется также аттестационный лист гражданского служащего с данными предыдущей аттестации. Значение отзыва выражается в том, что он является одним из главных письменных документов, подтверждающим факт выполнения или невыполнения аттестуемым гражданским служащим возложенных на него трудовых обязанностей. Следовательно, отзыв лежит в основе признания гражданского служащего соответствующим или не соответствующим занимаемой должности. (Заварихина, 2009: 41).

Т. е. именно руководитель государственного гражданского служащего может дать оценку деятельности государственного гражданского служащего. Вместе с тем, существуют и отрицательные моменты предоставления отзыва непосредственного руководителя. Не исключается ситуация наличия между непосредственным руководителем и подчиненным конфликта. В данном случае непосредственным руководителем может быть 
представлен негативный отзыв на гражданского служащего.

Чтобы выполнить принцип объективности при проведении аттестации государственного гражданского служащего, необходимо, чтобы аттестационная комиссия рассмотрела непосредственного руководителя исключительно во взаимосвязи с показателями эффективности и результативности профессиональной служебной деятельности гражданского служащего, закрепленными в должностном регламенте служащего. Такой подход минимизирует субъективизм при оценке деятельности государственного гражданского служащего. Что касается пояснительной записки, ее целесообразно представлять в случае несогласия гражданского служащего с оценкой его непосредственного руководителя. Гражданскому служащему в данном случае предоставляется возможность дать необходимые пояснения, а также предоставить соответствующие доказательства.

Гражданские служащие, замещающие должности гражданской службы категорий «руководители» и «помощники (советники)», не подлежат аттестации в случае, если с ними заключен срочный служебный контракт. Считаю, что логично представлен исключение из состава аттестуемых гражданских служащих тех, кто занимает должности гражданской службы категорий «руководители» и «помощники (советники)», в случае, если с указанными гражданскими служащими заключен срочный служебный контракт, а срочный служебный контракт предполагает временное замещение гражданином государственной гражданской должности. Признание аттестационной комиссией государственного служащего не соответствующим занимаемой государственной должности может повлечь постановку вопроса о его профессиональной переподготовке либо с его согласия о переводе на нижестоящую (другую) должность или об увольнении.

В соответствии с пп. 10-11 Положения о проведении аттестации государственных гражданских служащих РФ, утвержденного Указом Президента РФ от 01.02.2005 г. № 110, график проведения аттестации ежегодно утверждается представителем нанимателя и доводится до сведения каждого аттестуемого гражданского служащего не менее чем за месяц до начала аттестации. В графике проведения аттестации указывается: 1) наименование государственного органа, подразделения, в котором проводится аттестация; 2) список гражданских служащих, подлежащих аттестации; 3) дата, время и место проведения аттестации; 4) дата представления в аттестационную комиссию необходимых документов с указанием ответственных за их представление руководителей соответствующих подразделений государственного органа.

Согласно п. 3 Положения о проведении аттестации государственных гражданских служащих РФ от 01.02.2005 г. № 110, требование об обязательном проведении аттестации один раз в три года не распространяется 
на гражданских служащих: а) проработавших в занимаемой должности гражданской службы менее одного года (это связано с тем, что гражданский служащий, проработавший менее одного года, не приобрел необходимый опыт, в связи с чем объективно оценить его деятельность не представляется возможным); б) достижение возраста 60 лет (в данном случае проведение аттестации нецелесообразно, т. к. с указанными государственными гражданскими служащими заключается срочный служебный контракт); в) беременные женщины; г) находящиеся в отпуске по беременности и родам и в отпуске по уходу за ребенком до достижения им возраста трех лет; д) замещающие должности гражданской службы категорий « руководители» и «помощники (советники)», с которыми заключен срочный служебный контракт; е) в течении года со дня сдачи квалификационного экзамена.

Положение о проведении аттестации государственного служащего, находящегося на соответствующей должности государственной должности, устанавливает порядок проведения аттестации. Для проведения аттестации правовым актом государственного органа формируется аттестационная комиссия; утверждается график проведения аттестации; составляются списки федеральных государственных служащих, подлежащих аттестации; подготавливаются необходимые документы для аттестационных комиссии. Согласно п. 10 ст. 24 Ф3 «О государственной гражданской РФ» в состав аттестационной комиссии включаются представитель нанимателя и (или) уполномоченные им гражданские служащие (в том числе из подразделения по вопросам государственной службы и кадров, юридического подразделения и подразделения, в котором гражданский служащий, подлежащий аттестации, замещает должность гражданской службы), представитель соответствующего органа по управлению государственной службы, а также представители научных и образовательных учреждений, других организаций, приглашаемые органом по управлению государственной службы по запросу представителя нанимателя в качестве независимых экспертов-специалистов по вопросам, связанных с гражданской службы, без указания персональных данных экспертов. Число независимых экспертов должно составлять не менее $1 / 4$ от общего числа членов аттестационной комиссии. Данная норма закреплена в п. 8 Положения о проведении аттестации государственных служащих РФ, утвержденного указом Президента РФ от 01.02.2005 г. № 110.

Что касается состава аттестационной комиссии для проведения аттестации гражданских служащих, замещающих должности, исполнение обязанностей по которым связано с использованием сведений, составляющих государственную тайну, то он формируется с учетом положений законодательства РФ о государственной тайне. Частью 10 данной статьи 
устанавливаются требования к составу аттестационной комиссии. В состав аттестационной комиссии включаются: а) представитель нанимателя и уполномоченные им гражданские служащие (в том числе из подразделения по вопросам государственной службы и кадров, юридического подразделения и подразделения, в котором гражданский служащий, подлежащий аттестации, замещает должность гражданской службы), таким образом, личное участие представителя нанимателя является его правом, а не обязанностью; в состав аттестационной комиссии включаются уполномоченные представителем нанимателя гражданские служащие из кадровых и юридических структурных подразделений; б) представитель соответствующего органа по управлению государственной службой (в случае отсутствия органа по управлению государственной службой, указанный представитель в состав аттестационной комиссии не включается, и его функции выполняет представитель нанимателя); в) представители научных и образовательных учреждений, других организаций, приглашаемые органом по управлению государственной службой по запросу представителя нанимателя в качестве независимых экспертов-специалистов по вопросам, связанным с гражданской службой, без указания персональных данных экспертов. Как правило, указывается на наличие в составе комиссии независимых экспертов-специалистов и их число. Ю.А.Розенбаум подчеркивает, что формирование независимой и высококвалифицированной аттестационной комиссии является главнейшим условием проведения качественной оценки государственного служащего (Розенбаум, 1998: 25).

По общему правилу представитель нанимателя обязан направить органу по управлению государственной службой запрос о необходимости привлечения к работе аттестационной комиссии независимых экспертов. Орган по управлению государственной службой обращается в научные, образовательные и иные учреждения соответствующего профиля, и данные учреждения вправе самостоятельно определять персональный перечень сотрудников, которые будут принимать участие в деятельности аттестационной комиссии. Следует отметить, что независимые эксперты-специалисты привлекаются к работе в аттестационных комиссиях на возмездной основе. Вопрос оплаты их труда на федеральном уровне регулируется Постановлением Правительства РФ от 12.08.2005 г. № 509 «О порядке оплаты труда независимых экспертов, включаемых в составы аттестационной и конкурсной комиссии, образуемых федеральными государственными органами», и их почасовая оплата составляет 80 рублей. В Кировской области, например, имеется нормативно правовой акт - Постановление Правительства Кировской области от 16.03.2010 г. № 43/85 «Об оплате труда независимых экспертов, включаемых в составы аттестационной, конкурсной комиссий». Оплата труда независимых 
экспертов осуществляется на основе договора, заключенного между государственным органом и независимых экспертом.

Также нельзя не отметить п. 12 чт. 48 данного закона, то, что состав аттестационной комиссии формируется таким образом, чтобы была исключена возможность возникновения конфликтов, которые могли бы быть в аттестационной комиссии, его членство в этой организации приостанавливается. Представляется, что при формировании аттестационной комиссии невозможно предусмотреть все возможности возникновения конфликта интересов. Также законодателем предусмотрено, что на время аттестации гражданского служащего, являющегося членом аттестационной комиссии, его членство в этой аттестационной комиссии приостанавливается. Это связано с тем, что гражданский служащий не может одновременно проходить аттестацию и выполнять обязанность члена аттестационной комиссии. Также необходимо отметить, что аттестация гражданского служащего проводится при обязательном личном присутствии служащего.

Значение аттестационной комиссии довольно велико, именно в аттестационную комиссию предоставляются все документы, необходимые для аттестации, именно данная комиссия проводит аттестацию гражданского служащего и принимает решение о соответствии или несоответствии занимаемой должности государственного служащего. В связи с чем, аттестационная комиссия в своей деятельности должна руководствоваться следующими принципами: 1) принцип объективности, под которым понимается вынесение аттестационной комиссией объективных решений, основанных на всестороннем изучении представленных документов. Формальное отношение членов аттестационной комиссии к рассмотрению указанных документов может привести к нарушению принципа объективности, повлечь за собой вынесение субъективного решения; 2) принцип гласности, под которым подразумевается открытость деятельности аттестационной комиссии для всех заинтересованных сторон; 3)принцип компетентности. Данный принцип реализуется путем включения в состав аттестационной комиссии специалистов в области государственной службы и кадров, юристов; 4) принцип независимости, а именно независимость членов аттестационной комиссии от интересов представителя нанимателя или аттестуемого государственного гражданского служащего. Данный принцип связан с принципом объективности, т. к. независимость членов аттестационной комиссии позволяет аттестационной комиссии выносить объективные решения о соответствии гражданского служащего занимаемой должности; 5) принцип доброжелательности и соблюдения норм профессиональной этики.

Сущность аттестационной деятельности рассматривается в прин- 
ципах аттестации. Они вырабатываются аттестационной практикой государственных органов. Аттестация государственных служащих строится на следующих основных принципах: внепартийность, гласность, систематичность аттестации; объективность и комплексность оценки; коллективность и обоснованность оценки и рекомендации аттестационной комиссии; обязательность принятия по результатам аттестации организационно-правовых мер ответственность и стимулирование.

Необходимо обратить внимание, что закон не устанавливает какиелибо ограничения по численности аттестационной комиссии. Полагаю, что численность аттестационной комиссии должна определяться в каждом конкретном случае исходя из принципов эффективности и разумности.

В результате аттестации государственному гражданскому служащему дается одна из следующих оценок: 1) соответствует замещаемой должности государственной службы; 2) соответствует замещаемой государственной должности гражданской службы и рекомендуется к включению в установленном порядке в кадровый резерв для замещения вакантной должности гражданской службы в порядке должностного роста; 3) соответствует замещаемой должности гражданской службы при условии успешного прохождения профессиональной переподготовки или повышения квалификации; 4) не соответствует замещаемой должности гражданской службы.

Результаты аттестации заносятся в аттестационный лист гражданского служащего, который подписывается председателем комиссии, заместителем председателя, секретарем и членами аттестационной комиссии, которые присутствовали на заседании. Указанные результаты сообщаются аттестованным гражданским служащим непосредственно после подведения итогов голосования путем ознакомления с аттестационным листом под расписку. Аттестационный лист гражданского служащего, прошедшего аттестацию, и отзыв об исполнении им должностных обязанностей за аттестационный период хранятся в личном деле гражданского служащего. В соответствии с п. 21 Положения о проведении аттестации государственных гражданских служащих РФ, утвержденного Указом Президента РФ от 01.02.2005 г. № 110, секретарь аттестационной комиссии ведет протокол заседания комиссии, в котором фиксирует ее решения и результаты голосования. Протокол заседания аттестационной комиссии подписывается председателем, заместителем председателя, секретарем и членами аттестационной комиссии, присутствующими на заседании.

По результатам проведения аттестации служащего в течение одного месяца после ее проведения издается правовой акт государственного органа, предусматривающий: 1) включение гражданского служащего в кадровый резерв для замещения вакантной должности гражданской служ- 
бы в порядке должностного роста; 2) направление на профессиональную подготовку или повышение квалификации; 3) понижение в должности гражданской службы.

Согласно части 17 указанной статьи, предусматривается возможность отказа государственного служащего от профессиональной подготовки, повышения квалификации или от перевода на другую должность гражданской службы. При этом указание каких-либо причин для этого не требуется. В данном случае представитель нанимателя вправе освободить гражданского служащего от замещаемой должности гражданской службы и уволить его с гражданской службы в соответствии с п. 6 ч. 1 ст. 33 Ф3-79 «О государственной гражданской службе РФ».

При этом, необходимо отметить, что п. 24 Положения о проведении аттестации государственных гражданских служащих РФ, установлен пресекательный срок для реализации представителем нанимателя права уволить гражданского служащего с гражданской службы, перевести его на другую должность. В частности, по истечении одного месяца после проведения аттестации перевод гражданского служащего на другую должность гражданской службы, либо увольнение его с гражданской службы по результатам данной аттестации не допускается. При этом время болезни и ежегодного оплачиваемого отпуска гражданского служащего в указанный срок не засчитывается.

Кроме того, отказ гражданского служащего от профессиональной переподготовки, повышения квалификации или от перевода на другую должность гражданской службы должен быть оформлен в письменном виде, т. к. в случае возникновения спора представитель нанимателя должен будет предоставить доказательства, подтверждающие факт такого отказа. По итогам аттестации предусмотрено и принятие решение о соответствии гражданского служащего замещаемой должности гражданской службы при условии успешного прохождения профессиональной переподготовки или повышения квалификации. При этом Положением об аттестации не определены сроки выполнения указанного условия. К тому же если профессиональная переподготовка предполагает приобретение дополнительных знаний и навыков, необходимых для осуществления гражданскими служащими нового вида профессиональной служебной деятельности (Государственные требования к профессиональной переподготовке, п. 9. 2008, ст. 2194). Считаю, что необходимо в Положении об аттестации закрепить правило, в соответствии с которым рассматриваемое условие подлежит исполнению в течении определенного срока, например 1-2 года с момента проведения аттестации, или срока, устанавливаемого самой аттестационной комиссией. В части профессиональной переподготовки гражданского служащего по результатам аттестации, полагаю, что 
принятие данного решения аттестационной комиссией возможно только при проведении внеочередной аттестации по решению представителя нанимателя. Сложно согласиться с мнением С. Н. Булгакова, что «такой подход к использованию аттестации представляется принципиально неверным, поскольку искажает цель аттестации: вместо установления соответствия служащего занимаемой должности - оптимизация численности (т. е. изначально предполагается, что по итогам аттестации должны быть увольнения) (Булгаков, 2010: 354).

При рассмотрении данного вопроса, нельзя не сказать про право гражданского служащего оспаривать результаты аттестации. Данное право реализуется гражданским служащим в рамках индивидуального служебного спора. Порядок рассмотрения служебных споров в органах по рассмотрению служебных споров регулируются Ф3-79 «О государственной гражданской службе РФ» и другими федеральными законами. Порядок рассмотрения дел по служебным спорам в судах определяется гражданским процессуальным законодательством РФ. Но необходимо отметить, ГПК РФ не устанавливает порядок рассмотрении дел по служебным спорам. Подразумевается, что результаты аттестации (за исключением решения об увольнении гражданского служащего с гражданской службы) могут быть обжалованы в порядке, установленной главой 25 ГПК РФ, а решение об увольнении с гражданской службы - в порядке, предусмотренном для рассмотрения трудовых споров.

Заканчивая свою работу, хочется сказать, что под аттестацией государственных служащих понимается деятельность, в процессе которой аттестационная комиссия в рамках установленной научно обоснованной процедуры в целях выявления степени соответствия служащего занимаемой должности производит оценку деловых, личных и нравственных качеств служащего, процесса и итогов его служебной деятельности, результатами которой становятся оценка и рекомендации аттестационной комиссии по улучшению труда как аттестуемого лица, так и аппарата всего государственного органа. Аттестация необходима для регулярного определения уровня профессиональной подготовки служащего и степени ее соответствия квалификационным требованиям. Аттестация призвана способствовать формированию кадрового состава гражданской службы, повышению профессионального уровня гражданских служащих, решению вопросов, связанных с определением преимущественного права на замещение должности гражданской службы при сокращении должностей гражданской службы в государственном органе, а также проблем, связанных с изменением условий оплаты труда гражданских служащих. 


\section{СПИСОК ЛИТЕРАТУРЫ}

Антонова, Н. М. (2010) Проблемы юридической ответственности в контексте реализации конституционного принципа равного доступа к государственной службе в РФ // Государственная власть и местное самоуправление. № 5 .

Большой юридический словарь (1998) / под ред. А. Я. Сухарева, В.Д.Зорькина, В. Е. Крутских. М. : Инфра-М.

Булгаков, С. Н. (2010) Право государственных гражданских служащих на обжалование аттестации // Вестник ВГУ. Серия: Право. № 1.

Булыга, Н. Н. (2009) Аттестация: правовые основания и порядок проведения // Отдел кадров бюджетного учреждения. № 9.

Заварихина, С. А. (2009) Аттестация государственных служащих // Бухгалтерский учет в бюджетных и некоммерческих организациях. № 17.

Колесников, В. Л. (1999) Аттестация государственных служащих: технология, результативность, проблемы совершенствования // Эффективные технологии в системе государственного и муниципального управления. Майкоп ; Ростов н/Д.

Розенбаум, Ю. А. (1998) Проблемы оценки государственного служащего // Административное право и административный процесс: Старые и новые проблемы. № 8.

Юридический энциклопедический словарь (1984). М. : Советская энциклопедия.

Абрамов Игорь Анатольевич - аспирант кафедры уголовноправовых и специальных дисциплин Московского гуманитарного университета. Адрес: 111395, Россия, г. Москва, ул. Юности, д. 5. Эл. адрес: igorabramov2209@yandex.ru. Научный руководитель - д-р юрид. н., проф. М. М. Дикажев.

Abramov Igor' Anatolyevich, Postgraduate student, Department of criminal law and special disciplines, Moscow University for the Humanities. Postal address: 5 Yunosti St., 111395 Moscow, Russia. E-mail: igorabramov2209@ yandex.ru. Research advisor - M. M. Dikachev, Doctor of Law, Professor. 